\title{
Povezanost indeksa tjelesne mase i zadovoljstva tijelom kod mlađih odraslih muškaraca
}

1 Toni Babarović

1 Institut društvenih znanosti Ivo Pilar, Zagreb

\section{Sažetak}

Zadovoljstvo tijelom i tjelesnim izgledom kod odraslih muškaraca rijetko je istraživana tema. Češći problemi nezadovoljstva među ženama doveli su do smanjena interesa za proučavanje uzroka i posljedica nezadovoljstva tijelom kod muškaraca. Ipak, rijetka istraživanja koja su se bavila ovom temom utvrdila su da postoji samo drugačiji odnos između težine i zadovoljstva tijelom kod žena i muškaraca, ali da psihosocijalne posljedice nezadovoljstva mogu biti podjednake. Dok kod žena prevladava linearan odnos između zadovoljstva i tjelesne težine, odnosno žene povećane tjelesne težine izražavaju veće nezadovoljstvo, kod muškaraca se čini da je taj odnos zakrivljen. Muškarci koji imaju premalu tjelesnu težinu, kao i oni s prekomjernom težinom, izražavaju manje zadovoljstvo tjelesnim izgledom od onih primjerene težine.

Cilj ovog istraživanja bio je istražiti i provjeriti odnos između indeksa tjelesne mase i zadovoljstva težinom kod muškaraca mlađe odrasle dobi u Hrvatskoj. $U$ istraživanju je sudjelovalo 196 studenata u dobi od 18 do 29 godina. Sudionici su ispunjavali internetski upitnik o zadovoljstvu tjelesnom težinom i pružili samoiskaz o svojoj visini i težini na osnovi kojega je izračunan njihov indeks tjelesne mase (BMI). Dobiveni rezultati analizi- rani su primjenom linearnih i nelinearnih regresijskih modela i pokazalo se da zakrivljena, kvadratna funkcija znatno bolje opisuje odnos BMI-ja i zadovoljstva tijelom nego što to čini linearni model. Isto je potvrđeno analizom varijance kojom su uspoređivane grupe muškaraca sniženog, idealnog i povišenog BMI-ja po zadovoljstvu težinom. Muškarci s niskim i visokim BMI-jem izražavali su znatno manje zadovoljstvo tjelesnom težinom od onih s idealnom težinom. Time su potvrđena očekivanja o zakrivljenom odnosu između tjelesne težine i zadovoljstva tijelom kod muškaraca, što učvršćuje dosadašnje nalaze u ovom području.

Ključne riječi: zadovoljstvo tijelom, zadovoljstvo tjelesnom težinom, indeks tjelesne mase (BMI), muškarci

Datum primitka: 05.06.2017.

Datum prihvaćanja: 15.06.2017.

DOI: $10.24141 / 3 / 1 / 4$

Adresa za dopisivanje:

Toni Babarović

Institut društvenih znanosti Ivo Pilar,

Marulićev trg 19/1, 10000 Zagreb

E-pošta: toni.babarovic@pilar.hr

Tel: +38514886800 


\section{Uvod}

Većina dosadašnjih istraživanja zadovoljstva tjelesnim izgledom, njegovih odrednica i korelata fokusirala se na žensku populaciju. Nalazi takvih studija imaju velikih ograničenja u primjeni na populaciji muškaraca, a često niti ne istražuju relevantne faktore koji mogu utjecati na zadovoljstvo tijelom kod muškaraca. Vjerojatni uzrok smanjenom interesu za istraživanje ove teme među muškarcima jest čest nalaz da su muškarci prosječno zadovoljniji svojim tjelesnim izgledom od žena. ${ }^{1}$ Iz toga je izvedena pretpostavka da problem nezadovoljstva tjelesnim izgledom nije ozbiljan problem za muškarce. Međutim, novija su istraživanja pokazala da se nezadovoljstvo tjelesnim izgledom kod muškaraca samo odvija u drugačijem psihosocijalnom kontekstu, ali da može imati jednako ozbiljne psihosocijalne ili zdravstvene posljedica kao i kod žena. ${ }^{1}$

Nedvojbeno je da suvremeni ideal mršavosti ima utjecaj na oba spola, ali implikacije kršenja društveno utvrđene norme o idealnoj težini različite su za muškarce i žene. Društvo izjednačava mršavost s ljepotom i atraktivnošću kod žena, ali ne koristi tjelesnu težinu kao središnji kriterij za procjenu atraktivnosti kod muškaraca. Ove različite norme dovode i do različitih praksi prilikom želje za gubitkom tjelesne težine kod muškarca i žena. Muškarci se često okreću vježbanju i izgradnji tijela postajući sve mišićaviji, dok žene najčešće pribjegavaju redukciji unosa hrane., ${ }^{1,2}$ Također je moguće da se priroda odnosa između tjelesne mase i zadovoljstva tijelom razlikuje kod muškaraca i žena. Ako postoji ideal snažnog i mišićavog muškaraca, tada muškarci koji su vrlo mršavi, ali i oni koji su pretili mogu biti nezadovoljni svojom težinom i tjelesnim izgledom u usporedbi s onima srednje tjelesne građe.

Budući da prekomjerna tjelesna težina, ali i premalena težina mogu biti čimbenici rizika za nezadovoljstvo tijelom kod muškaraca, rana istraživanja koja su pretpostavljala postojanje linearne povezanosti između indeksa tjelesne mase i zadovoljstva tijelom mogla su dovesti do podcjenjivanja tog odnosa. ${ }^{3}$ Neka novija istraživanja provedena na djevojčicama i dječacima utvrdila su da linearna povezanost između zadovoljstva tjelesnim izgledom i indeksa tjelesne mase postoji među djevojčicama, dok je među dječacima taj odnos bolje opisan takozvanom U-krivuljom. ${ }^{4}$ Utvrđeno je da dječaci s vrlo malom tjelesnom masom, kao i oni sa znatno poveća- nom tjelesnom masom iskazuju veću razinu nezadovoljstva tjelesnim izgledom od onih primjerene tjelesne težine. ${ }^{5,6}$ Izgleda da takav zakrivljeni odnos između tjelesne težine i zadovoljstva vlastitim tijelom vrijedi i za muškarce mlađe odrasle dobi. ${ }^{7,8}$

Cilj je ovog istraživanja ispitati odnos između zadovoljstva tjelesnom težinom i indeksa tjelesne mase na uzorku mlađih odraslih muškaraca u Hrvatskoj. Očekuje se zakrivljeni odnos između zadovoljstva izgledom i indeksa tjelesne mase, gdje će muškarci s niskim, kao i oni s visokim indeksom iskazivati veće nezadovoljstvo tijelom od onih s primjerenom tjelesnom težinom. Nalazi ovog istraživanja pridonijet će boljem razumijevanju nezadovoljstva tjelesnom težinom kod muškaraca, što je u dosadašnjoj znanstvenoj literaturi nedovoljno istražena tema.

\section{Metoda}

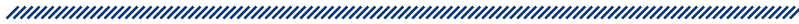

\section{Uzorak}

U istraživanju je sudjelovalo 196 muškaraca mlađe odrasle dobi u rasponu od 18 do 29 godina, prosječne dobi od 22,1 godine (SD =2,04). Sudionici su bili studenti različitih fakulteta Sveučilišta u Zagrebu.

\section{Postupak}

Istraživanje je provedeno internetskim anketnim upitnikom, a sudjelovanje u istraživanju je bilo dobrovoljno. Za ispunjavanje upitnika i davanje osobnih podataka bilo je potrebno desetak minuta, a ispitanicima je bila zagarantirana potpuna anonimnost.

\section{Mjere}

Indeks tjelesne mase (engl. Body Mass Index, BMI) korišten je kao pokazatelj debljine za čiji je izračun upotrijebljena samoprocjena visine i težine o kojoj su izvijestili sudionici u upitniku. BMI je izračunan tako da je težina u kilogrami- 
ma podijeljena s kvadratom visine u metrima. $\mathrm{Na}$ ovom uzorku ispitanika prosječan BMI iznosi 23,95 uz standardnu devijaciju od 2,59 te s minimumom od 16,61 i maksimumom od 31,51. Distribucija ove mjere na promatranom uzorku znatno ne odstupa od normalne distribucije. Dodatno je u svrhu nekih analiza primijenjena klasifikacija mjere BMI-ja Svjetske zdravstvene organizacije (WHO), na način da su ispitanici s indeksom tjelesne mase ispod BMI-ja 20 svrstani u grupu pothranjenih, oni s BMI-jem od 20 do 25 u skupinu s idealnom težinom, oni s BMI-jem od 25 do 30 u skupinu s prekomjernom tjelesnom masom, a oni s BMI-jem većim od 30 u skupinu pretilih.

Skala zadovoljstva tjelesnom težinom jedna je od podljestvica upitnika Zadovoljstva tjelesnim izgledom za adolescente i odrasle (Body-Esteem Scale for Adolescents and Adults - BESAA ${ }^{9}$ ). Podljestvica je namijenjena mjerenju zadovoljstva tjelesnom težinom i sastoji se od osam čestica (npr. „Stvarno mi se sviđa moja težina” ili „Vaganje me rastužuje”) i primjerena je za primjenu na uzorcima adolescenata i odraslih osoba. Ispitanici odgovaraju na pitanja na skali Likertova tipa od 0 (nikada) do 4 (uvijek). Utvrđena je dobra test-retest pouzdanost upitnika na uzorku ispitanika starijih od 12 godina, ${ }^{9}$ a na našem uzorku skala pokazuje jasnu jednofaktorsku strukturu s visokom pouzdanošću tipa unutarnje konzistencije od $a=0,894$. Rezultat na skali izražen je kao prosjek zbroja svih osam čestica na skali od 0 do 4 .

\section{Rezultati}

Deskriptivni podatci na ovom uzorku mlađih odraslih muškaraca pokazuju očekivane rezultate s obzirom na raspon i prosjek indeksa tjelesne mase i rezultata na skali zadovoljstva tjelesnom težinom (tablica 1). Zadovoljstvo tjelesnom težinom procjenjuju prosječno nešto većim od polovišta skale $M=2,54$ (skala od 0 do 4 ), što ukazuje na to da su umjereno zadovoljni svojom tjelesnom težinom. Ispitanici su također većinom unutar granica idealne tjelesne težine prema indeksu tjelesne mase, što je također vidljivo i iz njihove raspodjele u kategorije prema BMI-ju (tablica 2). Njih 117 (59,7 \%) spada u kategoriju onih s idealnom tjelesnom težinom, 66 $(33,7 \%)$ u skupinu s prekomjernom tjelesnom masom, dok se samo njih $11(6,1 \%)$ može smatrati pothranjenima. U skupinu pretilih prema vrijednosti BMI-ja i kate- gorizaciji Svjetske zdravstvene organizacije spada samo jedan sudionik u ovome istraživanju. Navedeni rezultati odgovaraju očekivanjima, s obzirom na to da je riječ o uzorku zdravih muških osoba mlađe odrasle dobi.

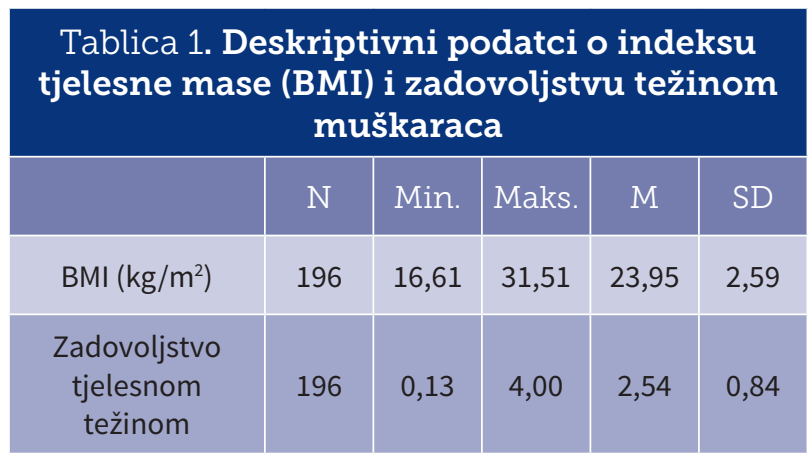

\begin{tabular}{|c|c|c|}
\hline & $\mathrm{N}$ & $\%$ \\
\hline Pothranjeni & 12 & 6,1 \\
\hline Idealna težina & 117 & 59,7 \\
\hline Prekomjerna tjelesna masa & 66 & 33,7 \\
\hline Pretili & 1 & 0,5 \\
\hline
\end{tabular}

Cilj je ovog istraživanja bio utvrditi kakav je odnos između indeksa tjelesne mase i zadovoljstva tjelesnom težinom kod mlađih odraslih muškaraca. U tu se svrhu opaženi odnos između dvije promatrane varijable pokušao modelirati linearnim i zakrivljenim aproksimacijama. Provedena je regresijska analiza kojom se pokušalo predvidjeti zadovoljstvo tjelesnom težinom na osnovi BMI-ja linearnim modelom te zatim kvadratnom funkcijom. Linearni model pretpostavlja da se odnos između dvije varijable (prediktora - X i kriterija - Y) može opisati linearnom jednadžbom $Y^{\prime}=a+b X$ uz minimalna rezidualna odstupanja. Kvadratni model pretpostavlja da odnos među varijablama nije linearan te da se može dobro opisati kvadratnom funkcijom $Y^{\prime}=a+b_{1} X^{2}+b_{2} X$. Uspješnost prognoze pojedinim modelom može se izraziti sumom kvadratnih odstupanja prognozirane vrijednosti na osnovi regresijske jednadžbe i stvarnih rezultata u kriteriju $\Sigma\left(Y-Y^{\prime}\right)^{2}$. Što su takva rezidualna odstupanja manja, model bolje odgovara stvarnim podatcima. Za lakšu interpretaciju uspješnosti prognoze upotrebljava se izvedeni koeficijent determinacije $\mathrm{R}^{2}$ koji govori koliki je udio (proporcija) varijabiliteta u kriterijskoj varijabli objašnjen primijenjenim modelom. Njegova statistička značajnost testira se pripadajućim F-omjerom. 
Slika 1. prikazuje odnos BMI-ja i zadovoljstva tjelesnim izgledom u našem uzorku sudionika. Stvarni rezultati pojedinaca prikazani su točkama na grafičkom prikazu. Punom i iscrtkanom linijom prikazane su linearna i zakrivljena (kvadratna) aproksimacija tog odnosa. Iz tablice 3 vidljivo je da linearnom prognozom uspješno možemo objasniti samo $1,6 \%\left(R^{2}=0,016\right)$ varijabiliteta zadovoljstva tjelesnim izgledom na osnovi indeksa tjelesne mase. Test značajnosti takve prognoze ukazuje na to da se linearnom funkcijom ne može previdjeti zadovoljstvo tjelesnim izgledom na osnovi BMI-ja kod mlađih odraslih muškaraca $\left(F_{(1,194)}=3,08 ; p=0,081\right)$.

Prognoza provedena kvadratnom funkcijom kao rezultat ima obrnutu U-krivulju kojom pokušava aproksimirati odnos između BMI-ja i zadovoljstva tjelesnim izgledom. To znači da je kod malog BMI-ja zadovoljstvo težinom nisko, zatim da raste, a svoj vrhunac doseže kod skupine s idealnom težinom (BMI od 20 do 25). Zadovoljstvo tijelom zatim ponovno pada s povećanjem BMI-ja. Uspješnost je prognoze ovog odnosa takvom kvadratnom funkcijom veća i iznosi $R^{2}=0,164$, što znači da se na s pomoću takve funkcije $16,4 \%$ varijabiliteta u zadovoljstvu tjelesnim izgledom može predvidjeti na osnovi BMI-ja. Ovakva je prognoza i statistički značajna $\left(F_{(2,193)}=18,89 ; p<0,001\right)$. Iz navedenih se podataka može zaključiti da kvadratna funkcija znatno bolje opisuje odnos BMI-ja i zadovoljstva tjelesnom težinom kod muškaraca mlađe odrasle dobi, gdje su najzadovoljniji težinom oni s umjerenim BMI-jem, a manje oni niskim ili visokim indeksom tjelesne mase.

Kako bismo dodatno provjerili postojanje zakrivljenog odnosa među promatranim varijablama, provjerena je razlika u zadovoljstvu tjelesnim izgledom između muškaraca svrstanih u različite kategorije prema BMI-ju,
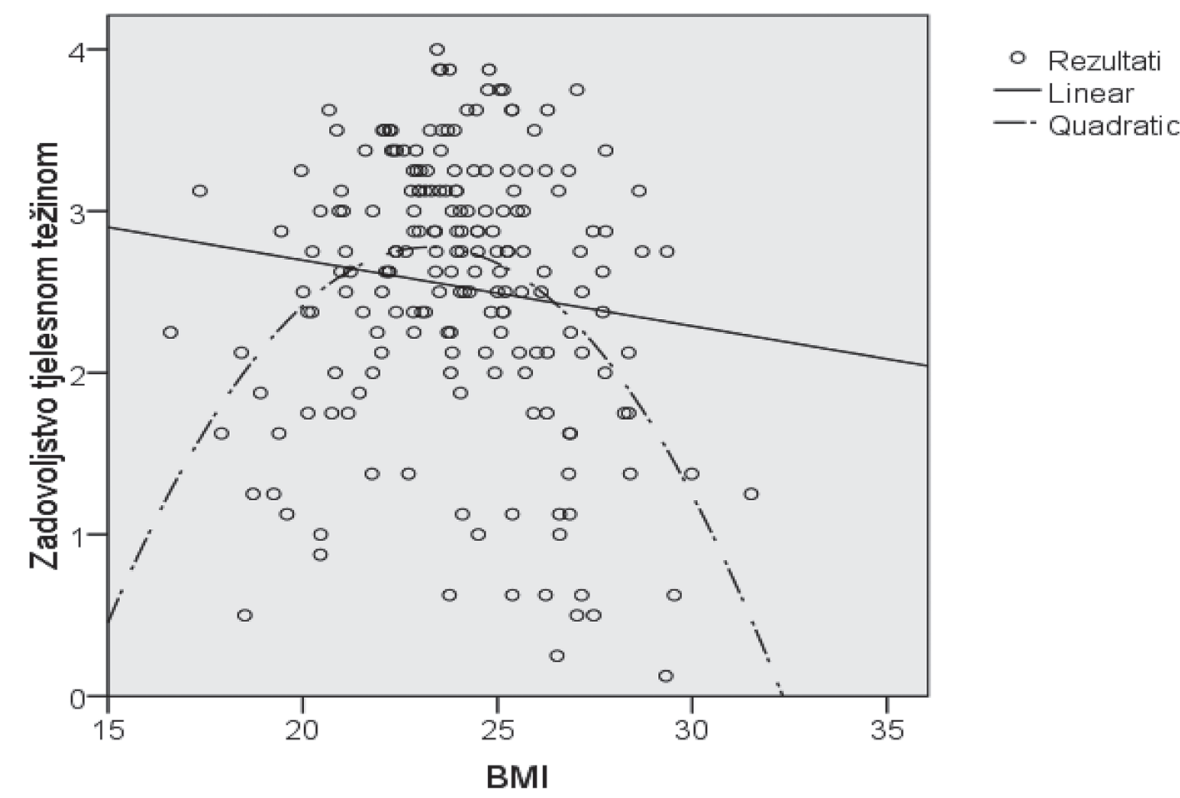

Slika 1. Odnos indeksa tjelesne mase i zadovoljstva tjelesnom težinom te aproksimacija tog odnosa linearnom i kvadratnom jednadžbom

Tablica 3. Uspješnost prognoze odnosa indeksa tjelesne mase i zadovoljstva tjelesnom težinom s pomoću linearne i kvadratne jednadžbe

\begin{tabular}{c|c|c|c|c|c|c|c|c|}
\hline \multirow{2}{*}{ Jednadžba } & \multicolumn{4}{|c|}{ Adekvatnost modela podatcima } & \multicolumn{3}{c}{ Regresijski parametri } \\
\cline { 2 - 9 } & $\mathrm{R}^{2}$ & $\mathrm{~F}$ & $\mathrm{df1}$ & $\mathrm{df2}$ & $\mathrm{p}$ & $\mathrm{a}$ & $\mathrm{b} 1$ & $\mathrm{~b} 2$ \\
\hline Linearna & 0,016 & 3,075 & 1 & 194 & 0,081 & 3,511 & $-0,041$ \\
\hline Kvadratna & 0,164 & $18,887^{\star}$ & 2 & 193 & 0,000 & $-15,595$ & $1,579^{\star}$ & $-0,034$ \\
\hline${ }^{*} \mathrm{p}<0,001$ & & & & &
\end{tabular}


metodom analize varijance. $\mathrm{U}$ analizi su upotrijebljene tri grupe ispitanika (Pothranjeni, Idealna težina i Prekomjerna tjelesna masa), dok je jedan ispitanik iz grupe Pretili isključen iz analize.

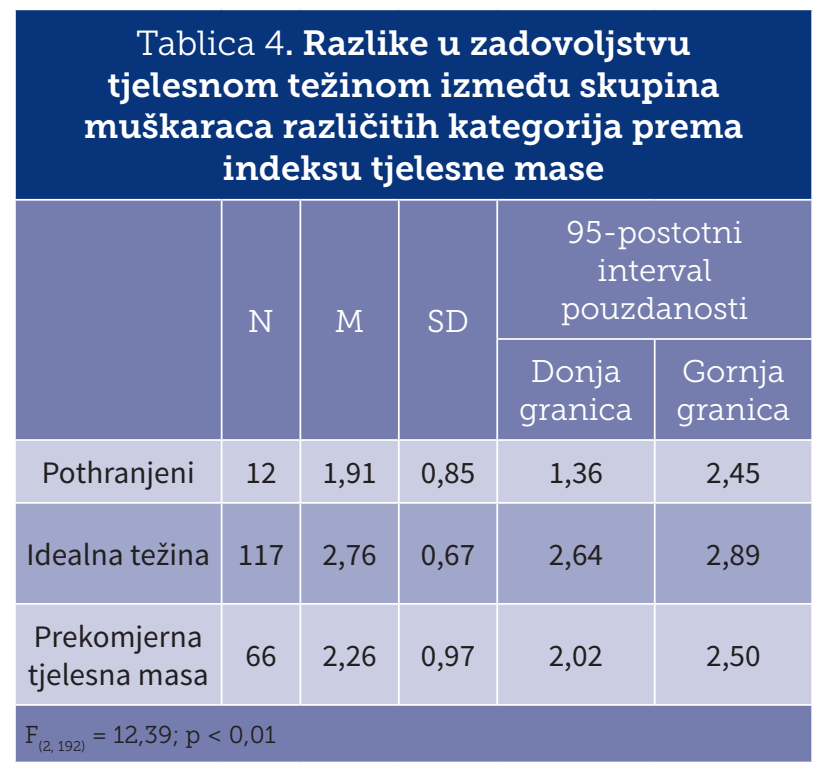

Usporedbom aritmetičkih sredina triju skupina (tablica 4 i slika 2) vidljivo je da ispitanici iz grupe s idealnom težinom imaju naviše prosječne rezultate na skali zado- voljstva tjelesnom težinom ( $M=2,76)$, ispitanici iz grupe s prekomjernom tjelesnom masom imaju niže prosjeke $(M=2,26)$, kao i oni iz grupe pothranjenih $(M=1,91)$. Među ovim grupama postoji statistički značajna razlika $\left(F_{(2,192)}=12,39 ; \mathrm{p}<0,001\right)$, što je vidljivo iz usporedbe raspona intervala pouzdanosti aritmetičkih sredina (tablica 4). Dakle, može se zaključiti da su ispitanici idealne tjelesne težine znatno zadovoljniji težinom od ostale dvije skupine, koje se međusobno ne razlikuju.

Provedena analiza grupnih razlika potvrđuje postojanje zakrivljenog odnosa između BMI-ja i zadovoljstva tjelesnom težinom, gdje najveće zadovoljstvo imaju muškarci primjerene tjelesne težine, a niže zadovoljstvo oni s niskim i visokim indeksima tjelesne mase.

\section{Rasprava i zaključak}

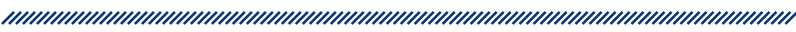

Nalazi ovog istraživanja podupiru ranije nalaze o postojanju zakrivljenog odnosa između tjelesne težine i zadovoljstva tjelesnim izgledom kod muškaraca. ${ }^{4-6,8}$ Promatrani odnos može se opisati obrnutom U-krivu-

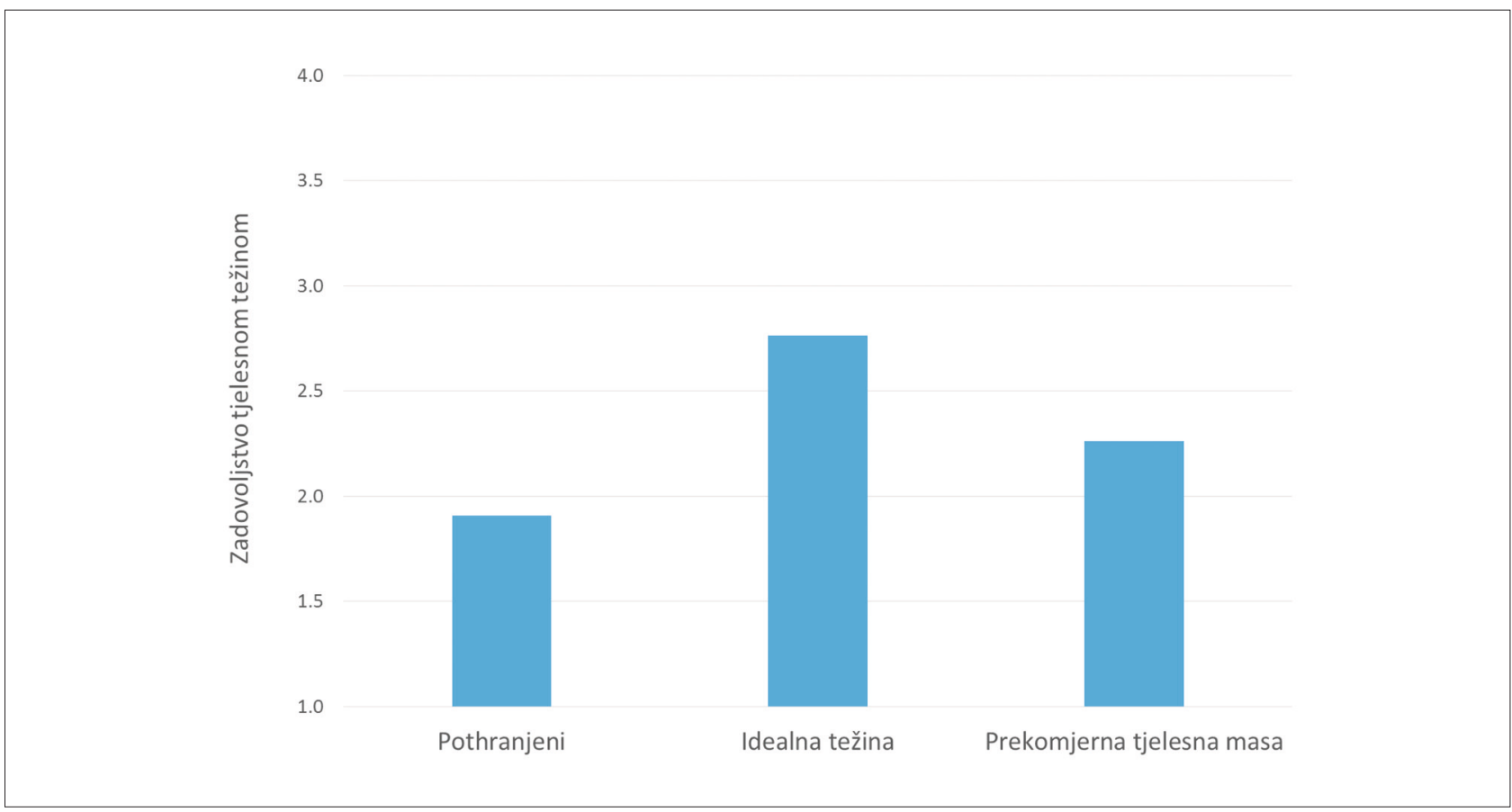


ljom, gdje muškarci umjerene tjelesne težine izražavaju najveće zadovoljstvo izgledom, a zadovoljstvo opada s povećanjem ili opadanjem tjelesne težine u odnosu na idealnu. Mogući uzroci ovakvih rezultata leže u znatnim sociokulturalnim pritiscima kojima su muškarci izloženi kako bi postigli željeni ideal moćnog i mišićavog muškarca. ${ }^{10}$ Mishkind i suradnicici ${ }^{11}$ pokazali su da muškarci doživljavaju znatne pritiske od strane vršnjaka, medija i drugih izvora kako bi ostvarili takozvani mišićni ideal te da zbog toga većina muškaraca doživljava nezadovoljstvo vlastitim tijelom. Izgleda da muškarci koji se ne uklapaju u takvu idealnu sliku izražavaju veliko nezadovoljstvo tijelom te posljedično postaju tjeskobni i ranjivi, ${ }^{12} \mathrm{~s}$ nižim samopoštovanjem i izraženijim depresivnim simptomima. ${ }^{13}$

Ipak, ovakvi se nalazi ne smiju isključivo pripisati pritiscima okoline na muškarce da postignu mišićavu, mezomorfnu građu. Zadovoljstvo tijelom nije jednostavno pitanje za odrasle muškarce, jer se ne odnosi samo na fizički izgled, nego i na njihovo zdravlje, kondiciju i opće zadovoljstvo životom. Zato bi se, prije nego što se zadovoljstvo tijelom kod muškaraca pripiše isključivo estetskim faktorima, trebalo utvrditi u kojoj je mjeri zadovoljstvo tijelom povezano s njegovom funkcionalnošću i fizičkim sposobnostima.

Nedostatci ovog istraživanja ponajprije proizlaze iz prigodnog i relativno malog uzorka ispitanika te autoselekcije onih koji su pristali sudjelovati u istraživanju. Ipak, normalna raspodjela sudionika s obzirom na indeks tjelesne mase te dobiveni rezultati koji su konzistentni s onima iz literature upućuju na to da se vjerojatno nije radilo u znatnije pristranom uzorku mlađih odraslih muškaraca s obzirom na promatrane konstrukte. Osim obilježja uzorka, dodatno ograničenje ovih nalaza možemo pronaći u jednostrukoj operacionalizaciji tjelesnih obilježja, odnosnom manjkom dodatnih antropometrijskih mjera. Tjelesna su obilježja u ovom radu mjerena jedino indeksom tjelesne mase, pa su stoga mnogi faktori, kojima bi se moglo objasniti zadovoljstvo tijelom kod muškaraca, ostali izvan ovog istraživačkog okvira. Nije, na primjer, mjerena mišićna masa, širina leđa, struka ni druge mjere koje bi pomogle u procjeni tjelesne građe i koje bi mogle dodatno objasniti zadovoljstvo tjelesnim izgledom. Ipak, uz navedena ograničenja, možemo zaključiti da dobiveni rezultati podržavaju spoznaje o zakrivljenom odnosu između zadovoljstva tijelom i tjelesne težine kod muškaraca. Muškarci s niskim i visokim indeksom tjelesne mase manje su zadovoljni svojim tijelom od onih s idealnom težinom i u uzorku hrvatskih studenata.

\section{Literatura}

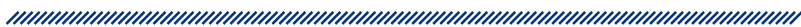

1. McCabe MP, Ricciardelli LA. Body image dissatisfaction among males across the lifespan: a review of past literature. Journal of Psychosomatic Research. 2004; 56: 675-685.

2. Furnham A, Calnan A. Eating Disturbance, Self-Esteem, Reasons for Exercising and Body Weight Dissatisfaction in Adolescent Males. European Eating Disorders Review. 1998; 6: 58-72.

3. Presnell K, Bearman SK, Stice E. Risk factors for body dissatisfaction in adolescent boys and girls: A prospective study. International Journal of Eating Disorders, 2004; 36 (4): 389-401.

4. Austin SB, Haines J, Veugelers PJ. Body satisfaction and body weight: gender differences and sociodemographic determinants. BMC Public Health. 2009; 9(1): 313-310.

5. Calzo, JP, Corliss H L, Blood EA, Field AE, Austin SB. Development of muscularity and weight concerns in heterosexual and sexual minority males. Health Psychology. 2013; 32: 42-51.

6. Kostanski M, Fisher A, Gullone E. Current conceptualisation of body image dissatisfaction: have we got it wrong? Journal of Child Psychology and Psychiatry. 2004; 45(7): 1317-1325.

7. Drewnowski A, Yee DK. Men and body image: are males satisfied with their bodyweight? Psychosomatic Medicine. 1987; 49(6): 626-637.

8. Muth JL, Cash T. Body-image attitudes: What difference does gender make? Journal of Applied Psychology. 1997; 27: 1438-1452.

9. Mendelson BK, Mendelson MJ, White DR. Body-esteem scale for adolescents and adults. Journal of Personality Assessment. 2001; 76(1): 901-906.

10. Gillett J, White PG. Male bodybuilding and the reassertion of hegemonic masculinity: a critical feminist perspective. Play Cult. 1992; 5: 358-369.

11. Mishkind ME, Rodin J, Silberstein LR, Striegel-Moore RH. The embodiment of masculinity: Cultural, psychological, and behavioral dimensions. American Behavioral Scientist. 1986; 29: 545-562.

12. McCabe MP, Ricciardelli LA. Sociocultural influences on body image and body change strategies among adolescent boys and girls. Journal of Social Psychology. 2003; 143(1): 5-26.

13. McCreary DR, Sasse DK. An exploration of the drive for muscularity in adolescent boys and girls. Journal of American College Health. 2000; 48: 297-304. 


\section{RELATIONSHIP BETWEEN BODY MASS INDEX AND BODY SATISFACTION IN YOUNG ADULT MEN}

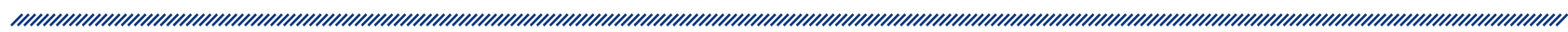

1 Toni Babarović

1 Institute of Social Sciences Ivo Pilar, Zagreb

\section{Summary}

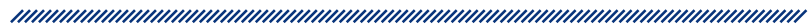

Body satisfaction and weight-related attitudes of adult men were not often explored. The more commonly manifested problems of female dissatisfaction have led to a reduction in interest in studying the causes and consequences of body dissatisfaction of men. Yet, rare research on this topic found that there is only a different relationship between weight and body satisfaction among men and women, but with similar psychosocial consequences of dissatisfaction. Women have a linear relationship between satisfaction and body weight, where women with increased body weight express greater dissatisfaction. In men samples, it seems that this relationship is curved. Overweight as well as underweight men express less body satisfaction comparing to men with normal weight.

The aim of this study was to investigate and test the relationship between body mass index and weight satisfaction in young adult men sample in Croatia. Participants were 196 students aged 18 to 29, from University of Zagreb. Participants filled out an online questionnaire on body weight satisfaction and were asked to provide their height and weight. From this data, a BMI score for each participant was calculated by using the BMI equation. The obtained data were analysed using linear and nonlinear regression models and it was shown that the curvilinear, square function better fit the data. The Ushaped curve depict the relationship between BMI and body satisfaction significantly better comparing to the linear model. The same was confirmed by the ANOVA procedure comparing the groups of underweight, normal-range and overweight men by their weight satisfaction. Men with low and high BMIs have been significantly less satisfied with their body weight than those of normal weight. These results confirm the expectations of the curved relationship between body weight and body satisfaction in men reinforcing the findings in the area.

Keywords: Body Satisfaction, Bodyweight Satisfaction, Body Mass Index (BMI), Men 